\title{
In vivo Study of Sister Chromatid Exchange and Cellular Kinetics in Bone Marrow Cells of Rana cotesbeiana
}

\author{
Jia F. Chen and Sue Y. Chai \\ Department of Biology, Chinese Culture University, Taipei, Taiwan, R. O. C.
}

Accepted December 1, 1989

Sister chromatid exchange (SCE) involves the reciprocal exchange of genetic material between sister chromatids at homologous loci. Analysis of the sister chromatid exchange frequencies induction both in vitro and in vivo have been proved a useful assay to detect a variety of potential mutagens or carcinogens (Perry and Evans 1975, Galloway et al. 1987). However most of the studies on SCE test were done in mammalian systems (Wolff 1977, Wilmer et al. 1984, Krishna et al. 1987). Recently, systems in chick embryo (Bloom and Hsu 1975), mussel (Harrison and Jones 1982), marine fish (Maddock et al. 1986) and toad (Chakrabarti et al. 1984) were developed for SCE assays.

Contamination of aquatic area became serious and aroused more of our attention. Enormous amount of herbicides and insecticide are commonly used in rice field in Taiwan. Frogs were hard to survive in aquatic area or rice field and were frequently found dead in polluted field (Chen 1987). Environmental toxic agents could threaten the life of these animals, caused severe effects on them and finally deteriorate our ecosystems. Genotoxic and cytotoxic effects of environmental pollutants in amphibians demand investigation. However, no in vivo SCE and cellular kinetics assay has been thoroughly developed for frogs. The amphibian selected for this study was the bullfrog, Rana catesbeiana, originated from North America. Since they were hard to survive in the open field, they were man-raised in Taiwan. Comparing to other species of native frogs, bullfrogs are of large size and of large numbers of bone marrow cells which made them easy to be harvested for analysis.

The objectives of this research are: 1) To develop a sister chromatid differentiation technique in bullfrog for biological monitoring of mutagens. 2) To investigate the effects of cyclophosphamide, an antitumor agent and a carcinogen as well on cellular kinetics and SCE frequencies in bullfrogs.

\section{Materials and methods}

\section{Animals and chemicals}

Male bullfrogs (Rana catesbeiana $2 \mathrm{~N}=26$ ) weighing $200-250 \mathrm{~g}$ were supplied by specialized animal dealers and were kept at $20-25^{\circ} \mathrm{C}$. Cyclophosphamide, 5-bromodeoxyuridine and other chemicals were from Sigma.

\section{Differential staining of sister chromatids}

Little data have been published pertaining to the cell cycle of frog bone marrow cells. Bullfrogs were very delicate and could not survive from long term consecutive injections or continuous intravenous infusion in our preliminary tests. To reduce stress on bullfrogs, a schedule of DNA labelling with 5-bromodeoxyuridine (5-BrdU) by multiple injection at the beginning of each cell cylcle was designed. The experimental protocol used for differential staining of sister chromatids is shown in Fig. 1. 5-BrdU dissolved in phosphate buffer saline (PBS, pH 6.8) was injected $50 \mathrm{mg} / \mathrm{kg}$ body weight $/ \mathrm{h}$ every hour for 10 consecutive doses at the 
beginning of each presumed cell cycle for two cell cycles.

Colchicine prepared in PBS $(20 \mathrm{mg} / \mathrm{kg}$ ) was injected intraperitoneally at the end of the second cell cycle. Animals were sacrificed 12-16 hr. later and bone marrow cells were aspirated through a 22 gauge needle into a $5 \mathrm{ml}$ syringe containing $3 \mathrm{ml}$ of PBS from the severed femurs. The mixture of bone marrow and PBS was dispensed into $5 \mathrm{ml}$ centrifuge tubes and mixed vigorously to assure dissociation of the cells. Slides were prepared following the methods of Chen and Lin 1986.

\section{Effects of chemicals on cellular kinetics and SCES}

Cyclophosphamide was dissolved in distilled water. Based on our preliminary test, 30 hr. was assumed to be the length of each cell cycle (see results). Single dose of chemical was injected half an hour before the second cell cycle. Cells dividing for the first (M1), second (M2), third or more $(\mathrm{M} 3+)$ times in vivo containing 5-BrdU were determined by the differential

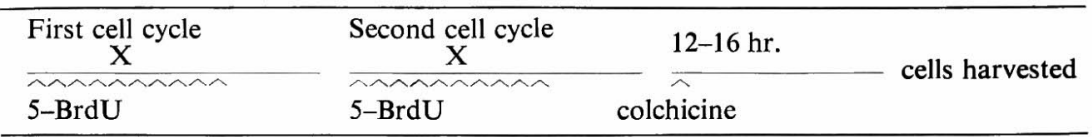

Fig. 1. Experimental protocol used for differential staining of sister chromatids. $X$ represents the duration of cell cycle we presumed. In these experiments $X$ was set at 15, 18, 21, 24, 27, 30, 33, 36,39 and $42 \mathrm{hr}$.

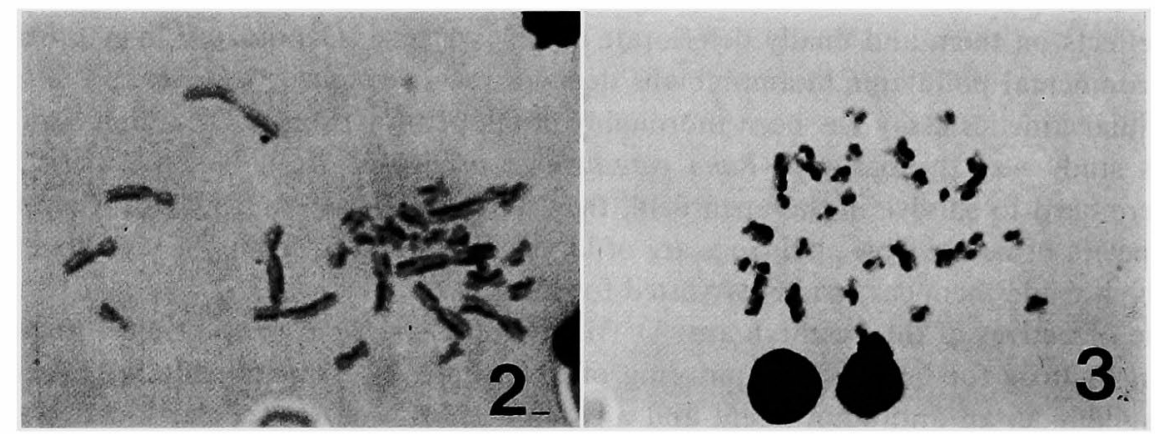

Figs. 2, 3. 2, a M2 bone marrow cell of Rana catesbeiana showing 26 differential staining chromosomes. 3, a M2 bone marrow cell showing 14 SCEs.

staining pattern of sister chromatids (Morimoto and Wolff 1980). For SCEs analysis, 20 M2 metaphase cells per animal were selected for scoring. At least three animals were used for each treatment. The mean frequency of SCE in each metaphase was counted. The experimental data from all assays were compared to the control group using Student's $t$-test. General linear regression lines for dose and response were drawn using the equation $\mathrm{Y}=\mathrm{mX}+$ c. Correlation coefficient ( $r$ ) was also calculared between dose and SCE response or dose and replicative index.

\section{Results}

\section{Differential staining of sister chromatids}

Percentage of M1, M2 and M3 + cells obtained by the technique of discontinuous i. p. injection of 5-BrdU based on the protocol of Fig. 1. were listed in Table 1. Good quality sisterchromatid differentiation in second division metaphase was observed (Figs. 2, 3) with this me- 
thod. The frequency of M2 cells increased from $13 \%$ to $62 \%$ as the hypothetical cell cycle raised from 15 to $30 \mathrm{hr}$. With the presumed cell cycle set longer than $30 \mathrm{hr}$. there occurred a decrease in M2 cells and an increase in M1 cells (Table 1) at the time bone marrows were harvested. The percentage of M2 plus $\mathrm{M} 3+$ reached up to $71 \%$ when cell cycle were set to be $30 \mathrm{hr}$. (Table 1). The percentage of M2 plus $\mathrm{M} 3+$ cells declined as the presumed cell cycle was set longer than $30 \mathrm{hr}$. Since only M2 cells were available for SCEs scoring, $30 \mathrm{hr}$. were chosen as a reasonable duration of cell cycle for further testing of chemical. Also the data in Table 1 suggested that cell populations found in the bone marrow were not synchronous, for cells are at different stages of division.

Table 1. Cellular kinetics of bullfrog bone marrow cells after hourly iv vivo injection of 5-bromodeoxyuridine for 10 consecutive doses at the beginning of each hypothetical cell cycle for two cell cycles

\begin{tabular}{ccccc}
\hline \hline $\begin{array}{c}\text { Hypothetical cell cycle } \\
\text { (hr.) }\end{array}$ & M1 $(\%)^{*}$ & M2 $(\%)^{*}$ & M3 $(\%)^{*}$ & M2+M3 $(\%)$ \\
\hline 15 & 79 & 13 & 8 & 21 \\
18 & 62 & 30 & 8 & 38 \\
21 & 57 & 27 & 16 & 43 \\
24 & 65 & 15 & 20 & 35 \\
27 & 40 & 48 & 12 & 60 \\
30 & 29 & 62 & 9 & 31 \\
33 & 64 & 34 & 2 & 36 \\
36 & 71 & 26 & 3 & 29 \\
39 & 71 & 22 & 7 & 29 \\
42 & 70 & 25 & 5 & 30 \\
\hline
\end{tabular}

* Each datum represents the mean of two animals.

Table 2. Effects of cyclophosphamide on sister chromatid exchanges and cellular kinetics in bullfrog bone marrow cells

\begin{tabular}{crccccccc}
\hline Cyclophosphamide & $\begin{array}{c}\text { Range of } \\
\text { SCES/cell }\end{array}$ & $\begin{array}{c}\text { SCEs/cell } \\
\text { (mean } \pm \text { SEM) }\end{array}$ & $p$ & \multicolumn{2}{c}{ Melaphase (\%) } & \multicolumn{2}{c}{$\begin{array}{c}\text { Replicative } \\
\text { index }\end{array}$} \\
\hline 0 & $8-15$ & $10750 \pm 0522$ & - & M1 & M2 & M3 & \\
$1.0 \mathrm{mg}$ & $5-16$ & $11400 \pm 0964$ & - & 46 & 62 & 12 & 1.86 \\
$2.0 \mathrm{mg}$ & $8-22$ & $13850 \pm 0952$ & $p<001$ & 44 & 40 & 16 & 1.72 \\
$4.0 \mathrm{mg}$ & $10-26$ & $20.200 \pm 1.047$ & $p<0.001$ & 38 & 51 & 11 & 1.73 \\
$16.0 \mathrm{mg}$ & $-{ }^{*}$ & & & & & & & \\
\hline
\end{tabular}

* Not enough metaphase were available for scoring.

\section{Celluar kinetics and sister chromatid exchanges}

Percentages of M1, M2, M3+ of bone marrow from animals injected with cyclophosphamide at various doses were shown in Table 2. Replicative index represented the average number of replication cycles completed by a metaphase cell population and the mean replication rate was calculated in the following: $(\mathrm{Ml} \times 1+\mathrm{M} 2 \times 2+\mathrm{M} 3 \times 3) / 100$ (Schneider et al. 1781). M1, M2 and M3 are expressed as percentages. Treatment of cyclophosphamide at 1,2 and $4 \mathrm{mg} / \mathrm{kg}$ appeared to cause a slight effect on the duration of the cell cycles (Table 2). A dose dependent decrease in replicative index $(r=-0.847)$ was found.

As shown in Table 2, bullfrog bone marrows exhibited high spontaneous frequency of SCEs $(10.750 \pm 0.522)$. This may reflect the sensitivity of the cells to 5 -BrdU (Morgan and Crossen 1982, Morales-Ramirez et al. 1787). Table 2 shows the group mean SCE frequencies 
after the treatment of cyclophosphamide. The control mean SCE frequencies and the linear dose-response curves for the induction of SCE by cyclophosphamide are presented graphically in Fig. 4. Over the doses tested, cyclophosphamide induced a linear increase in SCE frequency. The correlation coefficient was 0.9982 . Threatment of 2.0 and $4.0 \mathrm{mg} / \mathrm{kg}$ cyclophosphamide induced a statistically significant increase in the SCE at $p<0.01$ and $p<0.001$, respectively. The least effective dose $(i . e$. the observed control SCE frequency divided by the slope of the least square line, Maddoch 1986) was $4.36 \mathrm{mg} / \mathrm{kg}$ for cyclophosphamide.

\section{Discussion}

Due to a long duration of the mitotic cell cycle in the bone marrow of amphibian, $96 \mathrm{hr}$. with $5-\mathrm{BrdU}$ in the medium was required for differential sister chromatid staining in cultured frog cells (Chao and Rosenstein 1984), $35 \mathrm{hr}$. of hourly $i$. p. injection of 5-BrdU was necessary for $53 \%$ of Indian toad bone marrow cells to show differential sister chromatid staining

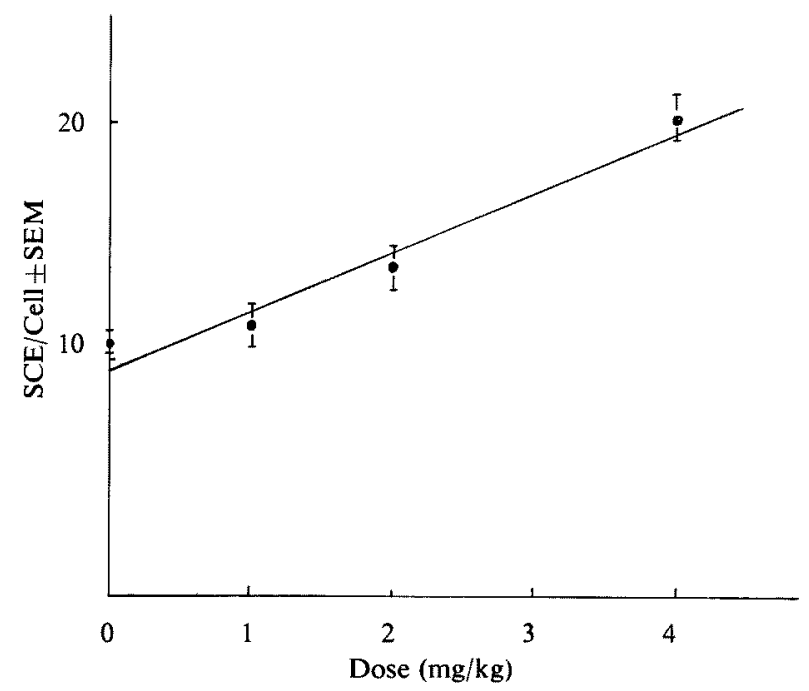

Fig. 4. Induction of SCEs by cyclophosphamide at doses of $0,1,2,4, \mathrm{mg} / \mathrm{kg}$. $Y=9.74+$ $(2.462858 \mathrm{X})$

(Chakrabarti et al. 1984). In our present study more than $70 \%$ of the bone marrow of bullfrogs with differential staining of sister chromatid can be obtained by the discontinuous 5BrdU administration method described in materials and methods. $S$ phase is the only period that DNA synthesis occurs in any given cell type. In order to insure the incorporation of 5-BrdU for two rounds of replication, 5-BrdU should be present at the time DNA synthesis occurred. The level of blood 5-BrdU concentration was determined by its pharmacokinetic properties. The high percentage of the second division cells by the 5-BrdU administration method used in this investigation had implied that 10 consecutive injections at the beginning of each cell cycle was enough to maintain high blood 5-BrdU concentration for the incorporation of this base analogue into the replicating DNA. The discontinuous $i . p$. injection protocol described here provides a convenient approach for eliciting high-quality sister-chromatid differentiation. As the injection schedule was set at $42 \mathrm{hr}$./cell cycle as described in materials and methods, $70 \%$ of the bullfrog bone marrow cells showed no differential staining of sister chromatids (Table 1). This indicated that the cell cycle of bullfrog bone marrow cells should 
be less than $42 \mathrm{hr}$.

In view of the schedule of $5-\mathrm{BrdU}$ administraion and the generation of M2 cells, it is believed that the cell cycle of in vivo bullfrog bone marrows should be around $30 \mathrm{hr}$. The total duration of exposure to 5 -BrdU (more than $10 \mathrm{hr}$. in each cycle) is sufficient for the incorporation of this base analogue into most bone marrow cell populations. Wang et al. 1986 reported that the peak value of differential sister chromatid staining in cultured toad Bufo bufo Gargarizans blood lymphocytes appeared at $72 \mathrm{hr}$. after the stimualation of phytohemagglutinin and the incubation of 5-BrdU. Similar results were observed in bullfrogs, the peak value of the M2 cells appeared at 74 to $76 \mathrm{hr}$. $\{(30+30+(12$ to 16$)\}$ after the first injection of 5-BrdU (Table 1).

Cyclophosphamide is a mutagen often used in in vivo tests as a postive control for chromosome aberration and SCEs (Allen et al. 1977). Cyclophosphamide does not damage chromosomes in vitro unless it is metabolized by microsomal enzyme (DeRatt 1977). In in-vivo test systems, positive results can be acquired without addition of microsomal enzymes. Species differences in their ability to activate cyclophosphamide were described (Brodk et al. 1971). Comparison of the sensitivity of different species to sister chromatid exchange induction by in vivo exposure to cyclophosphamide can be made. Comparing the least effective concentration for SCE induction to cyclophosphamide, $7.4 \mathrm{mg} / \mathrm{kg}$ was for toadfish kidney cells (Maddock et al. 1986) and $4.36 \mathrm{mg} / \mathrm{kg}$ was for bullfrog bone marrow cells (present study). It can be suggested that bullfrog bone marrow is a sensitive system for biomonitoring of the potent mutagens.

Cyclophosphamide caused a wide range of SCE frequencies in bullfrog bone marrow population as seen in Table 2. According to lihima and Morimoto 1986 with human lymphocyte, mytomycin $C$ and ethylmethanesulphonate induced higher SCE frequencies in S phase than cells at other stages of the cycle. Unsynchronization at the division cycle of bullfrog bone marrows (Table 2) will possibly explain the wide range of SCEs, since each animal was injected with single dose of chemical. The time, when chemicals were injected, will cause differences in their ability to induce SCEs, for the cells were at different stages of division.

\section{Summary}

A discontinuous 5-bromodeoxyuridine administration method which allowed in vivo sister chromatid exchanges assay in bullfrog bone marrows was developed. As a prototype of an in vivo mutagenesis test, this procedure was utilized to detect the genotoxic and cytoxic effects of cyclophosphamide. A dose-dependent increase in the frequeny of SCEs was observed. Cyclophosphamide caused a slight cell-cycle delay and a dose-dependent decrease in replicative index. The present study demonstrates that in vivo SCE method in bullfrogs can be used as a monitoring system for the assessment of environmental genotoxic chemicals.

\section{Acknowledgments}

This project was supported in part by National Science Council, Grant, no. NSC 770211-B-034-01, Taiwan, Republic of China.

\section{References}

Allen, J. W., Shuler, C. F., Mendes, R. W. and Latt, S. A. 1977. A simplified technique for in vivo analysis of sister-chromatid exchanges using 5-bromodeoxyuridine tablets. Cytogenet. Cell Genet. 18: 231237.

Bloom, S. E. and Hsu, T. C. 1975. Differential fuorescence of sister chromatids in chick embryo exposed to 5-bromodeoxyuridine. Chromosoma 51: 261-267. 
Brodk, N., Gross, R., Hohorst, H. J., Klein, H. O. and Schneider, B. 1971. Activation of cyclophosphamide in man and animals. Cancer 27: 1512-1529.

Chakrabarti, S., Banerjee, S. N. and Chakrabarti, A. 1984. In vivo sister chromatid exchanges in amphibia a convenient model for mutagenicity bioassay. Indian J. Exp. Bio. 22: 347-349.

Chao, C. C. K. and Rosenstein, B. S. 1984. Inhibition of the UV-induction of sister chromatid exchanges in ICR-2A frog cells by treatment with $\gamma$-rays. Mutation Res. 139: 35-39.

Chen, J. F. 1987. Land animal ecological investigation in Li Ger Industrial Estate I. Lan. in environmental impact assessment for Taiwan Plastic Inc. Chinese Culture University, pp. 1-27.

- and Lin, Y. J. 1986. Effects of cyclophosphamide and diets on sister chromatid exchange frequency. Cytologia $51: 671-678$.

DeRatt, W. K. 1977. The induction of sister chromatid exchange by cyclophosphamide in the presence of differently induced microsomal fractions of rat liver. Chem. Biol. Interact. 19: 125-131.

Galloway, S. M., Armstrong, M. J., Reuben, C., Colman, S., Brown, B. and Cannon, C. 1987. Chromosome aberrations and sister chromatid exchanges in Chinese hamster ovary cells: Evaluations of $108 \mathrm{chem}-$ icals. Environ. Mol. Mutagen. 10: 1-175.

Harrison, F. L. and Jones, I. M. 1982. An in vivo sister chromatid exchange assay in the larvae of the mussel Mytilus edulis: Response to 3 mutagens. Mutation Res. 105: 235-242.

lihima, K. and Morimoto, K. 1986. Cell-stage dependence of mutagen-induced sister chromatid exchanges in human lymphocyte cultures. Mutation Res. 162: 121-129.

Krishna, G., Nath, J. and Ong, T. 1987. Mitomycin C induced sister chromatid exchanges in vivo and in-vivoin-vitro in mice and Chinese hamsters. Environ. Mol. Mutagen. 10: 157-168.

Maddock, M. B., Northrup, H. and Ellingham, T. J. 1986. Induction of sister chromatid exchanges and chromosomal aberrations in hematopoietic tissue of a marine fish following in vivo exposure to genotoxic carcinogens. Mutation Res. 172: 165-175.

Morales-Ramirez, P., Rodriguez-Reyes R. and Vallarino-Kelly, T. 1987. Analysis of spontaneous sisterchromatid exchanges in vivo by three-way differentiation. Mutaion Res. 178: 49-56.

Morgan, W. F. and Crossen, P. E. 1982. A comparison of induced sister chromatid exchange levels in Chinese hamster ovary cells and cultured human lymphocyte. Environ. Mol. Mutagen. 4: 65-71.

Morimoto, K. and Wolf, S. 1980. Cell cycle kinetics in human lymphocyte cultures. Nature (London) 288: 604-606.

Perry, P. and Evans, H. J. 1975. Cytological detection of mutagen carcinogen exposure by sister chromatid exchange. Nature (London) $258: 121-125$.

Schneider, E. L., Nakanishi, Y., Lewis, J. and Sternberg, H. 1981. Simultaneous examination of sister chromatid exchanges and cell replication kinetics in tumor and normal cells. Cancer Res. $41: 4937-4975$.

Wang, D. X. S., Ding, H. and Wang, Y. 1986. Studies on sister chromatid exchange and cell kinetics in cultured toad Bufo bufo Gargarizans blood lymphocytes. Acta Zool. Sin. 32(1): 1-7.

Wilmer, J. L., Erexson, G. L. and Klegerman, A. K. 1984. Sister chromatid exchange induction in mouse B lymphocytes and $\mathrm{T}$ lymphocytes exposed to cyclophosphamide in vitro and in vivo. Cancer Res. 44: $880-884$.

Wolff, S. 1977. Sister chromatid exchange. Ann. Rev. Genet. 11: 183-201. 